\title{
The creation of a national contract for home parenteral nutrition
}

\author{
J. P. Baxter ${ }^{1}$, R. F. McKee ${ }^{1}$ and C. Wigham ${ }^{2}$ \\ ${ }^{1}$ The Scottish Home Parenteral Nutrition Managed Clinical Network, Ninewells Hospital, Dundee DD1 9SY \\ and ${ }^{2}$ National Procurement, NHS National Services Scotland EH12 9EB
}

A managed clinical network (MCN) for home parenteral nutrition (HPN) exists in Scotland to improve the services to patients receiving this treatment for severe intestinal failure. The MCN is guided by core principles ${ }^{(1)}$, which include exploring the network's potential to achieve value for money and improve service quality. Until recently HPN was arranged on either an individual-patient basis or a localcontract basis by each hospital having clinical care of these patients (in 2006, twelve hospitals and seventy-seven patients; one to twentytwo per hospital). No standard contract was used. Review of service levels from the commercial supplier was on an ad hoc basis. Financial arrangements varied ${ }^{(2)}$. National Procurement (NP) is the contracting group who form part of NHS National Services Scotland. NP sourcing activity ensures that products and services are fit for purpose and of top quality, using end users' clinical expertise and knowledge to develop continuous quality assurance and deliver best value for NHS Scotland. With this in mind it was decided to try to secure a national contract for HPN.

A tender specification was prepared and circulated for comments to all stakeholders (MCN members, chief pharmacists, clinical service managers) and NP prepared a national contract. The tender was operated in line with EU legislation on an electronic tender basis. A representative stakeholder group (nurses, doctors, dietitians, pharmacy and procurement staff) met to consider the tender approach and again to consider the tender responses and award the business using a scoring system of which $30 \%$ was related to cost issues, the remainder quality issues.

Within Scotland, all Health Boards but one have agreed to implement the new national contract. All patients now receive HPN at the new contracted price and Health Boards are invoiced on per diem rates. The implementation of this national contract for sixty patients has saved a total of $£ 668000$, an excess of $£ 11000$ per patient annually. A contract monitoring system has been put in place involving key performance indicators reported regularly to end users, contractor and NP.

A national contract has been secured for HPN in Scotland at a significant cost saving. Ongoing partnership between the stakeholders (including patients), NP and the HPN provider should improve the quality of the service.

1. Scottish Executive Health Department Letter 21 (2007) Enhancing the Role of Managed Clinical Networks, Edinburgh: Scottish Executive.

2. McKee RF, Baxter JP \& Pennington CR (2002). Clin Nutr, 4, suppl.1, 6. 